\title{
LETTERS
}

\section{Use physician-rating websites with caution}

I congratulate Paul Webster for his reflective article on "physician-rating websites" in CMAJ, which I absolutely support. ${ }^{1}$ For online ratings, a fair amount of skepticism is always better than blind trust. Consumer organizations in Germany recommend noncommercial, cost-free and ad-free portals, such as the Weisse Liste (https:// weisse-liste.de/de/), when looking for a suitable doctor. Therein, for example, the results are based on a scientifically developed survey, and there is no ranking of the supposedly "best" doctors. Commercial physician-rating websites that rely on advertising need to offer something to their financial backers and that may affect the findings.

Liu and colleagues have just published the nature and trends of online physician ratings in Canada in the Journal of Medical Internet Research. ${ }^{2}$ With regard to specialty and geographic practice location, the study is certainly interesting for CMAJ readers.

\section{Martin Hofmeister PhD}

Nutrition scientist, Department of Food and Nutrition, Consumer Centre of the German Federal State of Bavaria, Munich, Germany

Cite as: CMAJ 2018 July 23;190:E892. doi: $10.1503 / \mathrm{cmaj} .69475$

\section{References}

1. Webster P. Online ratings for doctors are flawed, but "not going anywhere." CMAJ 2018;190:E305-6.

2. Liu JJ, Matelski JJ, Bell CM. Scope, breadth, and differences in online physician ratings related to geography, specialty, and year: observational retrospective study. J Med Internet Res 2018; 20:e76.

Competing interests: None declared. 